\title{
The Genetic Basis of Lateralization
}

\author{
Marian Annett
}

In I. E. C. Sommer and R. S. Kahn (eds.), Language Lateralization and Psychosis. Cambridge University Press, Cambridge. Chapter 5, pp 73-86.

Address: Dr Marian Annett, School of Psychology, University of Leicester, Henry Wellcome Building, Lancaster Road, Leicester, UK LE1 9HN

Email: doc@le.ac.uk 


\section{Summary}

Modern theories of genetic influence on lateralization suggest that random or fluctuating asymmetry has an important role. Theories of directional asymmetry or chance can be distinguished from the right shift (RS) theory that accidental asymmetries are universal for bilaterally symmetrical organisms, but that in most humans left hemisphere advantage gives an incidental bias of the random distribution toward the right hand. Whereas many assume there is a true incidence of left-handedness, the RS theory suggests that degrees of hand preference map onto a continuous baseline of asymmetry that can be cut at any point to represent observed incidences of left-handedness. The parameters of the RS genetic model were derived from findings for speech lateralization in aphasics, supporting the argument that the relevant genetic locus is 'for' cerebral dominance, not handedness. Genetic predictions are given for two levels of parental left-handedness (10\% and 20\%). Studies of family handedness distinguishing for sex in both generations gave generally good fits where handedness was assessed by self-report, but more variable fits for indirect report of relatives' handedness. The tendency to find a higher proportion of left-handed children born to left-handed mothers than left-handed fathers is not likely due to X-linked inheritance, but rather to slightly stronger expression of the $R S+$ gene in females than males, and also under-reporting of left-handedness in mothers by righthanded children.

Monozygotic (MZ) twins discordant for handedness have led to doubts about genetic influence but these doubts are misplaced if random asymmetry affects every individual, twin and singleborn. The similarity of handedness distributions in MZ and dizygotic (DZ) twin pairs suggests that similar mechanisms are at work in both types of 
pair. Twins are more likely to be left-handed than the singleborn, by some $3-4 \%$. There is greater concordance in $\mathrm{MZ}$ than $\mathrm{DZ}$ pairs, but this is difficult to detect because variability due to accidental asymmetries is large, in comparison with the small genetic variability (due to the high prevalence of dextral genetic bias).

The inheritance of brain asymmetries is difficult to research but findings are consistent with models developed for handedness. There is a continuous normal distribution of asymmetry, biased in a typical direction with negative skew. A study of strength of language lateralization in families suggests genetic influence. Studies of asymmetries of cerebral anatomy and function in twins support theories of bias in a typical direction, which is reduced in the presence of left-handers. The theory that asymmetries occur at random in the absence of the typical pattern is consistent with findings for language and visuospatial functions. The suggestion that the $R S+$ gene might lose directional coding and cause random impairment of the cerebral hemispheres offers a possible explanation for disorders of language and loss of cerebral asymmetry in psychosis. 


\section{Introduction}

The search for genetic bases for handedness began almost 100 years ago. There is strong evidence for a gene for normal lateralization of the viscera. There is evidence for genetic influence on hand preference but some reject genetic arguments in favour of explanations in terms of pathology, culture or learning. The handedness of twins poses particular problems because conventional expectations about concordance in monozygotic (MZ) versus dizygotic (DZ) twin pairs appear not to be fulfilled. Whether there is a genetic basis for lateralization of the brain is difficult to research. However, the correlation between right-handedness and left hemisphere speech suggests that theory and research on handedness might offer clues to the inheritance of cerebral asymmetries.

Jordan (1911) suggested that left-handedness might be due to the recessive allele of a classic Mendelian locus. Studies of the families of students disproved this model because two left-handed parents ( $\mathrm{L}$ x L families) had many right-handed children (Chamberlain, 1928; Ramaley, 1913; Rife, 1940). Trankell (1955) showed that although these three studies differed in incidences of left-handedness, they gave consistent estimates for a recessive allele with imperfect penetrance (frequency about 0.40-.43). Current theories propose a recessive allele with imperfect penetrance in the sense that it is neutral for directional asymmetry and leads to a right- or left-handed phenotype by chance (Annett, 1972; Klar, 1996; McManus, 1985). There must be many ways in which genetic and non-genetic influences combine to determine asymmetries of early growth (Rutter et al., 2006). The task of this chapter is to try to discern the recipe.

\section{Theories of directional or chance asymmetry}


Layton (1976) studied a mutant strain of mice with a high frequency of situs inversus. He hypothesized that a gene for typical situs was lost and that a mutant $i v$ gene gave random bias to either side. Some twenty years later it was discovered that left-right orientation in early embryos depends on the directional beating of cilia which direct the flow of essential substances to one side (Nonaka et al., 1998). Situs inversus is associated with abnormal flow (Okada et al., 1999). In humans, situs inversus is associated with loss of ciliary motion (primary ciliary dyskinesia, PCD) and occurs in 50\% of affected cases, as in mutant mice.

Are the same genes involved in visceral and cerebral lateralization in humans? There is no increase in left-handedness in people with PCD (McManus et al., 2004). Tanaka et al. (1999) gave a dichotic listening test to 9 subjects with situs inversus and found 8 had typical right ear advantage. Kennedy et al. (1999) examined 3 individuals with situs inversus and found them strongly right-handed, with left hemisphere language by fMRI. Therefore, although similar models of directional asymmetry or chance have been proposed for asymmetries of gut and brain, the same genes are not likely to be involved.

McManus (1985) suggested a model for handedness like that of Layton (1976), a single locus with alleles coding for directional asymmetry $(D$, dextrality) or random asymmetry $(C$, chance). The model assumed heterozygote variability, with $C$ expressed in $50 \%$ of $D C$ genotypes and $25 \%$ becoming left-handed. In $C C$ genotypes there is $50 \%$ left-handedness while in $D D$ genotypes there is $100 \%$ right-handedness. McManus suggested a 'true' incidence $(7.75 \%)$ of left-handedness in the population. In actual data many different incidences occur and discrepancies from the true value were treated as 
error. In tests of the model, right- and left-handers were moved between genotypes to match observed incidences. The model cannot fail, therefore, unless observed incidences are very different from the supposed true incidence. With regard to cerebral dominance, $D$ is expected to give left hemisphere speech, while $C$ gives random specialization. $C$ is expressed in $50 \%$ of heterozygotes but independently of handedness. This implies that a large proportion of atypical speakers should carry the $D$ allele.

Klar (1996) proposed a version of the dextrality or chance model resembling that of the $i v$ gene most directly, a dominant allele for dextrality $(R)$ and a recessive allele $(r)$ for chance asymmetry. $R R$ and $R r$ genotypes are right-handed and $r r$ genotypes are right or left-handed by chance. All left-handers are of $r r$ genotype so that in L x L families $50 \%$ of children should be left-handed. Klar supported his theory by citing Rife (1940) where 6 out of 11 children in L x L families were left-handed. However, this high proportion is unusual (McManus \& Bryden, 1992). In three new samples there were 94 children in L x L families, of whom $37.2 \%$ were left-handed, significantly fewer than the $50 \%$ predicted by Klar (Annett, 2008).

Klar argued that Rife's (1940) data give the 'true' incidence of left-handedness in the population because the criterion was use of the left hand for any of several actions. More recent studies using the same criterion find higher incidences (below). In Rife's sample incidences differed for fathers, mothers, sons and daughters. Klar estimated gene frequencies from the proportion of left-handed sons, about $9 \%$, thus giving $18 \%$ in the population with rr genotype and gene frequency of about .43 . The parallel with the estimates of Trankell (above) and Annett (below) is striking, but the reasoning behind the 
estimate does not withstand scrutiny. Klar has not attempted to fit his model to other studies in the literature.

A basic problem is that frequencies of left-handedness vary widely. If preference is treated as a discrete variable, then incidences are unstable and theories are restricted in the range of incidences to which they apply.

\section{The Right Shift theory: Chance asymmetry for all plus directional asymmetry for most but not all}

The RS theory (Annett, 1972) developed through a series of stages of empirical research and theoretical analysis (Annett, 2002). The chief conclusion of the RS analysis was that the genetic agent is for cerebral dominance, not handedness.

Briefly, the theory suggests that degrees of hand preference map onto a nongenetic normal distribution of asymmetry for hand skill, a continuum of right minus left $(\mathrm{R}-\mathrm{L})$ skill. Accidental differences in the early growth of the body give differences between the sides, different for every individual and for every individual twin. An agent of left cerebral advantage $(R S+$ gene) displaces the accidental distribution of handedness in a dextral direction. The relative advantage to the left hemisphere probably depends on a disadvantage to the right hemisphere (Kilshaw \& Annett, 1983). All gene carriers are expected to develop left hemisphere speech but the mechanisms involved probably have additive effects (below). $R S$ - - genotypes are hypothesized to develop right or left hemisphere speech at random, and independently of handedness. There is no intrinsic link between cerebral lateralization and handedness, except as mediated by the $R S+$ gene. $R S$ - - genotypes are distributed for handedness about $\mathrm{R}-\mathrm{L}=0$, but many are evenly balanced between the sides and easily persuaded, therefore, to use the right hand for 
socially significant actions such as writing and eating. An important element of the model is the threshold, or cut-point along the continuum of asymmetry, which divides rightfrom left-handers. When $10 \%$ of the population is classified as left-handed, the threshold is to the left of zero (of the R-L distribution) and some $35 \%$ of $R S$ - - genotypes will be left-handed. When $16 \%$ of the population is left-handed, the threshold is near zero and about 50\% should be left-handed. For critical reviews of Annett (2002) see Corballis (2004), Crow (2004), Elias (2004), McManus (2004) and author's reply (Annett, 2004). It is important to emphasize that the RS genetic model was not developed by fitting parameters to studies of family handedness. Rather, it was discovered that parameters derived from studies of aphasics representative of the general population (Annett, 1975) could be applied to family data, using straightforward Mendelian laws of segregation. The RS model explains relations between handedness and cerebral speech laterality (Alexander \& Annett, 1996: Annett \& Alexander, 1996). The theory suggests that right hemisphere speakers $(9.27 \%$, see also Pederson et al. 1995$)$ represent $50 \%$ of $R S$ - - genotypes (18.54\%) and the square root of this value gives the frequency of the $R S$ - gene (0.43) and the $R S+$ gene (0.57). The extent of shift was estimated from the percentages of left-handers with right versus left hemisphere speech. This approach required an assumption of dominance for cerebral speech and also handedness, and did not distinguish for sex. Predictions for handedness in families were good for all studies available at that time (Annett, 1978) except Ramaley (1913). Fits were good for strict criteria (left-writing) and also generous criteria (nonright-handedness). The original dominant model remains more powerful that rival models (Annett, 1996). A worked example of the calculations was given (Annett, 2002, Appendix VIII). 
Further studies led to elaborations in terms of additive effects and sex differences. The genotype frequencies which follow from the above estimates of gene frequency $(R S$ $++, 3242, R S+-.4904, R S--.1854)$ have the interesting property that the heterozygote is the most frequent, and about as high as possible for a pair of alleles at a single locus. This suggests a genetic balanced polymorphism with heterozygote advantage. Evidence has been sought for advantages associated with the $\mathrm{RS}+$ gene for speech and language related abilities and perhaps costs for nonverbal abilities (review Annett, 2002; Smythe \& Annett, 2006). Research into a balanced polymorphism is beyond the scope of this chapter, except for possible relevance to psychosis, considered below. The important point here is that heterozygote advantage implies that for at least some purposes the expression of the $R S+$ gene must be greater in double than in single dose.

There are small differences in incidence between the sexes which suggest that the $R S+$ gene is expressed a little more strongly in females than males. Family data showed good fits to predictions if shift values were as follows (shifts of $0.0 \mathrm{z}, 1.0 \mathrm{z}, 2.0 \mathrm{z}$ for males and $0.0 \mathrm{z}, 1.2 \mathrm{z}$ and $2.4 \mathrm{z}$ for females, for the $R S--, R S+-$ and $R S++$ genotypes respectively). Annett (1999a) showed that when family data were collected by self-report (parents and children describing their own handedness) these shift parameters gave matching values for corresponding thresholds of males and females (fathers and mothers or sons and daughters in the same sample).

\section{Tests of the RS genetic theory on family data}

Annett (1999a) tested the additive model against 14 sets of family data in which sex was distinguished for parents and children. Annett (2008) tested three further samples. The calculations depend on Mendelian laws, as said above, but the genotype frequencies must 
be matched to thresholds which are defined by incidences (Annett, 2002 Appendix III). The genotype proportions predicted for children must be matched to the frequency of left-handedness observed for children. Appendix I gives two examples of the percentages of left-handed sons and daughters expected in family types $(\mathrm{R} x \mathrm{R}, \mathrm{R} \times \mathrm{L}$ etc. father $\mathrm{x}$ mother), when parental incidences are $10 \%$ and $20 \%$ and incidences for children range from $5-40 \%$. (Further predictions across a range of incidences are given by Annett, 2008). Graphical plots of the percentages would allow intermediate values to be interpolated.

Table 1 gives the predicted and observed percentages of left-handed children for the data of Ashton (1982). This was a large sample of individually questioned parents and children in Hawaii. There were differences between ethnic groups for the writing hand but not for the question 'any use of the left hand?' (The data in Table 1 combine 'left' and 'ambidextrous' responses in Ashton's Table 3.) Incidences for children (sons 16.6\%, daughters $14.3 \%$ ) were higher than for parents (fathers $9.0 \%$, mothers $7.6 \%$ ) as in all family studies. The expected proportions for family types are close to those given in Appendix I a (10\% for parents), for filial incidences at about 15\%. Exact predictions are given in Table 1. Chi square values were low, showing good fit. (For d.f. $=3$, chi square at the $5 \%$ level of confidence is 7.81 , the minimum value needed to show significantly poor fit.)

Table 2 makes a similar analysis for McGee and Cozad (1980). Parents and children completed a questionnaire and were classified as left-handed if they performed any of 10 actions with the left hand. This resembled the criterion of Rife (1940) but incidences here were very different (fathers $19.6 \%$, mothers $16.7 \%$, sons $27.3 \%$ and 
daughters $21.4 \%$ ). The percentages expected in family types were now close to those listed in Appendix I b, (20\% for parents) and around 25\% for children. Exact predictions and tests against observed percentages are given in Table 2. There were good fits for both sexes.

Annett (1999a) found good fits to predictions for these studies and 4 others where data were collected by self-report except for one marginally poor fit for sons. In 8 studies where parent and sibling data depended on student report, fits were more variable. Children tend to under-estimate left-handedness in parents (Porac \& Coren, 1979) and right-handers are more likely than left-handers to be inaccurate (Kang \& Harris, 1996; McGuire \& McGuire 1980). Annett (2008) found good fit to predictions for a relatively small self-report sample but poorer fits for two indirect report samples. One of the latter (McKeever, 2000) was not representative of students but inflated by the recruitment of left-handers for psychology experiments, giving an incidence of about $17.5 \%$. The parental incidence, reported by the students, was about $10 \%$. Of the 8 family analyses available for the McKeever sample (4 family types x two sexes), only one was markedly discrepant with RS predictions, a shortfall of left-handed sons in L x R families. McKeever (2004) interpreted these findings as showing an excess of left-handed sons in $\mathrm{R} x \mathrm{~L}$ families, but the fit for the latter to RS predictions was particularly good.

These analyses show that fits to the RS model were generally good in self-report samples. Discrepancies occurred in indirect report samples but varied between studies. Poor fits were probably due to sampling variations and inaccurate report of parental handedness, as considered further below.

\section{Is there an $\mathrm{X}$-linked gene for handedness?}


There is a small trend to higher frequencies of left-handedness in males than females but rarely statistically significant in individual studies. There is also a tendency to find more left-handed children in the families of left-handed mothers than fathers. McManus and Bryden (1992) suggested an elaboration of the McManus (1985) model, a rare X-linked recessive modifier gene, which suppressed the expression of the $D$ allele and thereby raised the proportion of left-handers. These proposals were not submitted to tests against findings for handedness in families, either for specific studies or combined data. Corballis (1997) asked whether there are genes for handedness located in the homologous regions of the X and Y chromosomes but considered this implausible. Jones and Martin (2000) showed that it was possible to model sex differences, either for additive genes located in the homologous regions, or for a recessive model of X-linked inheritance. It is possible to model any set of data, of course, with appropriate choice of parameters, but those used by Jones and Martin were not plausible theoretically, nor did the model fit the data well (Corballis, 2001; rejoinder Jones \& Martin, 2001). McKeever (2004) suggested a model with three alleles on the sex chromosomes to fit his own data. None of these attempts to model X-linked inheritance was tested against specific studies in the literature.

The RS analysis suggests that the observation of more left-handed children in $\mathrm{R} \mathrm{x}$ L than L x R families could be due to a Carter (1961) effect. That is, traits that are expressed less often in females than males tend to be observed more often in the relatives of affected females than affected males. Annett (1999a) found a greater number of lefthanded children in $\mathrm{R} x \mathrm{~L}$ families (than predicted by the Carter effect and the RS theory) only when parental incidences were low. It was not present in combined data when parental incidences were greater than $7 \%$, where there was rather a shortfall of left- 
handers in $\mathrm{L} x \mathrm{R}$ families. The apparent excess of left-handers in $\mathrm{R} x \mathrm{~L}$ families in combined data over all studies could be corrected by moving right-handed children from $\mathrm{R} \times \mathrm{R}$ to $\mathrm{R} \times \mathrm{L}$ families (on the assumption than right-handed children had under-reported left-handedness in mothers) such as to increase the maternal incidence by $1 \%$. The proportion of left-handed children in $\mathrm{R} x \mathrm{~L}$ families was then not greater than predicted (Annett, 1999a).

These analyses suggest there is no need to look for X-linked inheritance for asymmetry. The difference between the sexes and between the families of left-handed mothers and fathers is probably due to stronger expression of the $R S+$ gene in females. Stronger expression is probably a function of rates of growth and relative maturity at birth, greater in females than males, and in the singleborn than twins.

\section{Handedness in Twins}

Handedness in twin pairs is often given as a reason to doubt a genetic influence (Bishop, 2001; Coren 1992). It is clear that handedness cannot be determined directly by genes for right- and left-handedness or there would be no discordant MZ pairs, whereas about $20 \%$ are found (Collins, 1970). A similar percentage is found for DZ pairs, suggesting that similar mechanisms are at work in both types of twin. An interesting feature of the twin data is that the proportions of the three types of pairs are as expected by chance, the binomial proportions expected if right and left-handers were represented by black and white marbles, placed in a bag, and taken out in pairs at random. This feature of the data persuaded Collins that genetic inheritance was not possible, and he suggested (Collins, 1977) that culture might explain associations between parents and children. McManus 
(1980) concluded that while dizygotic twin pairs were binomial, MZ twins tended to have more LL pairs and fewer RL pairs than expected.

The idea that twins are more often left-handed than singletons has been controversial (Coren, 1992; McManus, 1980; Zazzo, 1960). However, when Annett (1978) discovered that a single gene could predict handedness in families, the same model could account for handedness in twin pairs, if the extent of shift were reduced in twins compared with the singleborn. The same reduction of shift was required for $\mathrm{MZ}$ and DZ pairs, showing that the effect was not genetic but a function of twinning. The reduced shift implied that twins should be more often left-handed than the singleborn by about $3-4 \%$. Rife $(1940,1950)$ found $12.4 \%$ of twins left-handed compared with $8.8 \%$ of students, on the same questionnaire. Davis and Annett (1994) examined the responses of some 30,000 people to a questionnaire on hearing disabilities, which included questions on handedness and twinning. There were more left-handers among twins in all age groups and overall there were $7.1 \%$ singleton and $11.7 \%$ twin left-handers. Sicotte et al. (1999) found by meta-analysis a higher incidence of left-handedness in twins than the singleborn.

The key argument, for most skeptics of genetic influence on handedness, is the discordance of $\mathrm{MZ}$ pairs. However, discordance is expected if the primary cause of handedness is accidental asymmetries of growth. If asymmetries arise between the two sides of the body in every individual, twin and singleton, a binomial distribution is expected in pairs of twins, or siblings. Does this mean there is no genetic influence? No, because the majority of twins are biased to the right, like the majority of singletons. The $R S+$ gene influences the growth of both twins, but at most thresholds of left-handedness, 
twins of the same genotype may be on different sides of the threshold. The similarity of $\mathrm{MZ}$ and DZ pairs is due to the fact that some $81.5 \%$ of twins of both zygosities are genecarriers. An exaggerated analogy may help to make the point. It is not concluded that there are no genes for upright walking because $\mathrm{MZ}$ and DZ twins all walk upright. Similarly, most twins are influenced by the $R S+$ allele.

\section{Inheritance of brain asymmetries}

An early attempt to study the inheritance of brain asymmetries used a dichotic listening test in 49 families (Bryden, 1975). Correlations were small between parents and children, and absent between siblings. Studies of cerebral asymmetries in the healthy population require reliable and noninvasive methods. Functional magnetic resonance imaging (fMRI) offered a relatively non-invasive approach (Pujol et al., 1999: Szaflarski et al., 2002). The assessment of language lateralization by functional transcranial Doppler ultrasonography (fTCD) allowed large numbers of healthy volunteers to be tested (Knecht et al., 2000b). Right hemisphere language dominance was found in $7.5 \%$ of healthy right-handers. Knecht et al. (2000a) examined atypical right hemisphere speech in relation to personal and family handedness. Incidences ranged from $4 \%$ for strong right-handers to $27 \%$ for strong left-handers. Within types of right- and left-handers there tended to be more right hemisphere speakers if there was a left-handed parent.

Are these findings consistent with expectations for $R S$ - - genotypes? The numbers of left- and right-handers expected for each of the three genotypes of the RS locus, at different levels of incidence, were tabulated in terms of Ns per 1000 (Annett, 2002, Appendix III). When 10\% (100) of the population is classified as left-handed some 65/185 RS - - genotypes are left-handed and the remaining 120 right-handed. By chance, 
half of $R S$ - - are expected to develop right hemisphere speech, so that $32.5 / 100(32.5 \%)$ of left-handers and 60/900 (6.7\%) of right-handers should have right hemisphere speech. When $20 \%$ of the population is left-handed the expected incidences of right hemisphere speech are $26.5 \%$ in left-handers and $4.9 \%$ in right-handers. These values approximate those found by Knecht et al.

An association for strength of language lateralization between relatives was sought by fTCD in 10 families (Anneken et al., 2004). In 2 families where both parents were strongly lateralized 3 children were also strongly lateralized. By contrast in 2 families where neither parent was strongly lateralized none of the 3 children were strongly lateralized. In 6 families where parents differed, 8 of 14 children were strongly lateralized. Numbers were small, but this represents a first attempt to show familial segregation for strength of functional cerebral lateralization.

With regard to anatomical asymmetries Steinmetz et al. (1991) described the planum temporale (PT) in right and left-handers with and without family sinistrality. The trends were as expected if presence of left-handed relatives was associated with reduced asymmetry. In left-handers with left-handed relatives overall asymmetry was absent, consistent with the hypothesized $R S$ - - genotype.

Is it likely that models developed for handedness are applicable to cerebral dominance? An important question is the nature of the underlying distributions, continuous or discrete? The describing relations between speech laterality and handedness it is often necessary to classify cases in discrete categories such as the presence or absence of aphasia, or handedness left or right. However, the underlying distributions of asymmetry for hand and brain are probably continuous. For over 300 
cases described by Knecht et al. (2001) the distribution of fTCD asymmetry was continuous and approximately normal with negative skew. There was a small mode to the left of $\mathrm{L}=\mathrm{R}$ but this is expected as Knecht et al. recruited extra left-handers. The distribution resembles that for differences in the internal lengths of the left and right halves of the cranium (Hoadley \& Pearson, 1929) and asymmetry for peg moving (Annett, 1992). Other measures of hand skill for which participants use a pen or pencil give a bimodal distribution, but this is not surprising following practice in writing. The overall conclusion is that functional cerebral asymmetry resembles other asymmetry distributions in being continuous, the mean displaced in a typical direction from $\mathrm{R}=\mathrm{L}$. What of the hypothesis that in the absence of directional shift cerebral functions assort at random? Flöel et al. (2001) looked for associations between language and spatial abilities, which typically lateralize to different hemispheres. In 10 cases of atypical right language laterality, spatial functions were localized to the left in 6 and to the right in 4 cases. Flöel et al. (2005) examined a further sample of left- and right-handers for language and spatial laterality. They found both functions lateralized to the left in 7 subjects and both to the right in 8 subjects. That is, all combinations of lateralization occur, about as expected for random assortment in atypical cases.

\section{Cerebral lateralization in twins}

When large samples of twins are reliably assessed for cerebral dominance, what proportions are expected? Annett (2003) described several predictions. Normally developing MZ twins of $R S++$ and $R S+-$ genotype are expected to be concordant for left cerebral speech (81.5\% of pairs). Chance assortment for cerebral dominance occurs in $R S$ - - pairs (18.5\%). Pairs of MZ twins are predicted, therefore, to assort for typical (T) and 
atypical (A) cerebral dominance as TT, TA and AA in the proportions $86.1 \%, 9.3 \%$ and $4.6 \%$ respectively. The corresponding predictions for DZ pairs are $83.8 \%, 13.8 \%$ and $2.4 \%$.

What of the predictions for cerebral lateralization if handedness is known? If both twins are right-handed (RR pairs) or one or both twins nonright-handed (non-RR pairs) Annett (2003) estimated that in MZ twins about $92 \%$ of RR pairs and $68 \%$ of non-RR pairs would be concordant for typical cerebral asymmetry. In DZ twins there should be about $89 \%$ of RR pairs and $69 \%$ of non-RR pairs concordant.

Geschwind et al. (2002) measured the volumes of left and right cerebral cortex in 72 pairs of MZ twins and 67 pairs of DZ twins, all male veterans of World War 2. Cerebral volumes were found highly heritable. In MZ twins, within pair correlations for total cerebral volumes, and also for left and right hemispheres, were significantly higher in RR than non-RR pairs. DZ twins did not show this difference but the number of nonRR DZ pairs was small. The important outcome was support for the thesis that there is a genetic influence on cerebral asymmetry in right-handed twin pairs that is diminished when one of the twins is left-handed.

Sommer et al. (2002) made a similar comparison between RR and non-RR pairs of MZ twins performing language tasks while undergoing fMRI. The lateralization index of the RR pairs was significantly larger than for the non-RR pairs. The within pair correlation of RR pairs for the lateralization index was significant but not for non-RR pairs. This pattern of findings resembles that of Geschwind et al., a strong bias to typical asymmetry in RR pairs and a marked reduction in typical bias in non-RR pairs. 
Steinmetz et al. (1995) measured PT asymmetries in 10 RR and 10 non-RR pairs of $\mathrm{MZ}$ twins. Within pair correlations were low for both sets of twins but right-handers tended to show the expected leftward asymmetry while left-handers had reduced asymmetry. Annett (2003) estimated that 9/10 RR pairs and 6/10 non-RR pairs, in this study, were concordant for typical asymmetry, consistent with predictions above.

\section{Non-genetic influences on human lateralization}

It is often pointed out that growth depends on a combination of genetic and environmental influences, but arguments about human handedness have tended to emphasize one to the exclusion of the other. Evidence for environmental influences on handedness (Orbeleke et al., 1996; Tambs et al., 1987) is often interpreted as implying no genetic influence. However, the RS theory assumes accidental environmental influences for everyone, but also a genetic influence in most people.

What non-genetic theories have been offered? The main suggestions include pathology (Coren, 1992), learning (Provins, 1997) culture (Collins, 1977) or a combination of variables (Perelle \& Ehrman 2005). With regard to pathology, it is obvious that serious disorders of growth may distort the processes of lateralization, as in cerebral palsies. No clear line can be drawn between normal and pathological accidents of development. It is not justified, however, to conclude that all left-handedness is pathological because some is pathological. In studies of family handedness, the influence of pathology was likely to be negligible. Right cerebral dominance, by fTCD, was associated with no evidence of pathology (Knecht et al., 2003).

Learning and culture influence the expression of handedness for actions such as eating and writing, but do not necessarily affect other behaviour. In personal testing of 
older people who had been forced to use the right hand for writing from childhood, relative hand skill and preference for actions other than writing remained strongly sinistral. That is, forced learning, cultural pressure and a lifetime of practice had no discernable effect on preference and skill for the left hand. Functional neuroanatomy for writing was studied by positron emission tomography in adults who had been forced to convert to right-handed writing and had used that hand exclusively since childhood (Siebner et al., 2002). There were persisting differences from natural right-handers, even after decades of using the right hand. Pressures against the use of the left hand remain strong in many cultures and probably persist to some degree in Western societies. For a typical threshold for left-handed writing (about $10 \%$ of the population) some $35 \%$ of $R S$ - genotypes are expected to be left writers, as explained above.

Yeo and Gangestad (1993) suggested that humans are designed to be moderate right-handers and that left-handedness and strong right-handedness are caused by developmental instability. They suggested that a tendency to developmental instability may be inherited. The prediction that strong right-handers have more left-handed parents than moderate right-handers (Gangestad \& Yeo, 1994) was not supported in two samples of students (Annett, 1996).

A "gene-culture" theory (Laland et al., 1995) has three key elements, chance asymmetries that influence everyone, an inherited bias toward right-handedness that also influences everyone but is not strong enough to induce right-handedness in all, and a cultural bias associated with the handedness of parents. The key point is that everyone has the same genotype. The gene-culture model raises the stakes for explanations of lateralization because it is necessary to look for genetic variability for traits not likely to 
be influenced by culture. It is not enough to cite associations between typical asymmetries and right-handedness because both might have been caused by a common directional bias.

A specific prediction of the gene-culture model is that there is no difference in concordance for handedness between $\mathrm{MZ}$ and DZ twins. A small but statistically significant difference was found by meta-analysis (Sicotte et al. 1999). An asymmetry unlikely to be influenced by culture is eye preference. Eye preference in children varies with eye preference in parents (Brackenridge, 1982). Segregation in families follows the same rules as for handedness, on the RS model (Annett, 1999b).

The effect of parental handedness was examined by Carter-Saltzman (1980) for the biological and adoptive children of left-handed parents. There was no raised incidence of left-handedness in the adoptive children although there was for the biological children. Annett $(1974,1983)$ measured hand preference and hand skill in the children of L x L parents and found the expected reduction of bias to right-handedness. In the families of parents with early history of trauma that might have led to pathological left-handedness, the children were as biased to dextrality as controls. That is, the experience of being raised by two left-handed parents did not counter the effect of the $R S$ + gene.

Genome-wide searches for loci associated with relative hand skill on the Annett peg moving task found evidence for a quantitative trait locus (QTL) on chromosome 2p12-11 (Francks et al., 2002; Francks et al., 2003). Francks et al. (2007) narrowed the locus further by describing an association between hand skill in siblings and a haplotype 
upstream of gene LRRTM1 (Leucine-rich repeat transmembrane neuronal 1) on chromosome $2 \mathrm{p} 12$ which is inherited paternally.

Search for a locus for hand preference found possible linkage to markers on chromosome 12q21-23 (Warren et al., 2006). Van Agtmael et al. (2001) found no evidence for linkage to chromosome 7 but possible linkage to chromosome 10 (Van Agtmael et al., 2002; Van Agtmael et al., 2003). Medland et al. (2006) found a genetic influence on handedness in twins, along with considerable individual variability.

The conclusion from these several lines of research must be that there are genetic influences on human lateralization, against a background of accidental asymmetries. The latter mainly give variation in the normal range, but developmental accidents may in some cases be severe enough to be called pathological. Culture moderates the expression of left- and right-handedness, but this is added to genetic and epigenetic influences.

\section{The theory of an agnosic $R S+$ gene in schizophrenia and autism}

Crow (1997) argued that schizophrenia, and perhaps other psychoses, arise from a disorder of the mechanisms of cerebral dominance. If the RS theory is correct in suggesting that there is only one systematic influence on cerebral dominance, then psychosis might depend on disorders of the $R S+$ gene. The gene is likely to be of recent origin in human evolution and might therefore be unstable and liable to mutation. Annett (1997) suggested that there could be a mutant in which directional coding is lost.

Whereas the normal form of the $R S+$ gene might give an instruction, "Impair the speech cortex of one cerebral hemisphere, the right", the mutant form might lose the last element and impair either hemisphere at random. When paired with a normal $R S+$ allele which impairs the right hemisphere, both hemispheres would be impaired in $50 \%$ of cases, 
while in $50 \%$ there would be double impairment of the right hemisphere (as in normal $R S++$ genotypes $)$.

If schizophrenia is associated with a single dose of impairment of speech cortex in both hemispheres there would be a problem with language, and also a loss of typical asymmetry. The chance rule shows how MZ twins could be concordant for schizophrenia in $50 \%$ of pairs while the non-schizophrenic twin in discordant pairs could be normal. Working through the probabilities, using the parameters of the RS model as already developed but with the addition of an agnosic allele (frequency 0.02), it was discovered that risks to relatives approximated those estimated by Gottesman (1991).

From the frequencies deduced above, it would follow that homozygotes for the agnosic gene would be about 4 per 10,000, about the rate estimated for autistics diagnosed by strict criteria (Rutter, 1991). Random assortment of cerebral functions would allow for many patterns of strengths and weaknesses in autistics, as well as a variety of patterns of symptoms in schizophrenia, but all associated with impairments of language functions. The implications of these ideas were reviewed, along with discussion of critical commentaries (Annett, 2002, ch.14).

If there is instability of the $R S+$ gene, making it liable to mutation associated with psychosis, this would be a powerful reason for limiting the spread of the gene in the population, as suggested by the balanced polymorphism hypothesis mentioned above. The idea of an agnosic $R S+$ gene remains speculative but deserves further scrutiny as new evidence becomes available. 


\section{References}

Alexander, M. P., \& Annett, M. (1996). Crossed aphasia and related anomalies of cerebral organization: Case reports and a genetic hypothesis. Brain and Language, 55, 213-239.

Anneken, K., Konrad, C., Dräger, B. et al. (2004). Familial aggregation of strong hemispheric language lateralization. Neurology, 63, 2433-2435.

Annett, M. (1972). The distribution of manual asymmetry. British Journal of Psychology, 63, 343-358.

Annett, M. (1974). Handedness in the children of two left-handed parents. British Journal of Psychology, 65, 129-131.

Annett, M. (1975). Hand preference and the laterality of cerebral speech. Cortex, 11, 305328.

Annett, M. (1978). A Single Gene Explanation of Right and Left Handedness and Brainedness. Coventry, UK: Lanchester Polytechnic.

Annett, M. (1983). Hand preference and skill in 115 children of two left-handed parents. British Journal of Psychology, 74, 17-32.

Annett, M. (1992). Five tests of hand skill. Cortex, 28, 583-600.

Annett, M. (1996). In defence of the right shift theory. Perceptual and Motor Skills, 82, $115-137$.

Annett, M. (1997). Schizophrenia and autism considered as the products of an agnosic right shift gene. Cognitive Neuropsychiatry, 2, 195-240.

Annett, M. (1999a). Left-handedness as a function of sex, maternal versus paternal inheritance and report bias. Behavior Genetics, 29, 103-114. 
Annett, M. (1999b). Eye dominance in families predicted by the right shift theory. Laterality, 4, 167-172.

Annett, M. (2002). Handedness and Brain Asymmetry: The Right Shift Theory. Hove, UK: Psychology Press.

Annett, M. (2003). Cerebral asymmetry in twins: predictions of the right shift theory. Neuropsychologia, 41, 469-479.

Annett, M. (2004). Perceptions of the right shift theory. Cortex, 40, 143-150.

Annett, M. (2008). Tests of the right shift genetic model for two new samples of family handedness and for the data of McKeever (2000). Laterality, 13, 105-23.

Annett, M. \& Alexander, M. P. (1996). Atypical cerebral dominance: Predictions and tests of the right shift theory. Neuropsychologia, 34, 1215-1227.

Ashton, G. C. (1982). Handedness: An alternative hypothesis. Behavior Genetics, 12 , $125-147$.

Bishop, D. V. M. (2001). Individual differences in handedness and specific language impairment: Evidence against a genetic link. Behavior Genetics, 31, 339-351.

Brackenridge, C. J. (1982). The contribution of genetic factors to ocular dominance. Behavior Genetics, 12, 319-325.

Bryden, M. P. (1975). Speech lateralization in families: A preliminary study using dichotic listening. Brain and Language, 2, 210-211.

Carter, C. O. (1961). Inheritance of congenital pyloric stenosis. British Medical Bulletin, 17, 251-253.

Carter-Saltzman, L. (1980). Biological and sociocultural effects on handedness: Comparison between biological and adoptive families. Science, 209, 1263-1265. 
Chamberlain, H. D. (1928). The inheritance of left handedness. Journal of Heredity, 19, $557-559$.

Collins, R. L. (1970). The sound of one paw clapping: An inquiry into the origin of left handedness. In G. Lindzey \& D. D. Thiessen (Eds.) Contribution to BehaviorGenetic Analysis - The Mouse as a Prototype (pp 115-136) New York: Appleton.

Collins, R. L. (1977). Origins of the sense of asymmetry: Mendelian and non-Mendelian models of inheritance. Annals of the New York Academy of Sciences, 299, 283305.

Corballis, M. C. (1997). The genetics and evolution of handedness. Psychological Review, 104, 714-727.

Corballis, M. C. (2001). Is the handedness gene on the X chromosome: Comment on Jones and Martin (2000). Psychological Review, 108, 805-810.

Corballis, M. C. (2004). Taking your chances. Cortex, 40, 115-117.

Coren, S. (1992). The Left-Hander Syndrome: The Causes and Consequences of LeftHandedness. London: John Murray.

Crow, T. J. (1997). Schizophrenia as a failure of hemispheric dominance for language. Trends in the Neurosciences. 20, 339-343.

Crow, T. J. (2004). What Marian Annett can teach Noam Chomsky and could have taught Stephen Jay Gould if he'd had time to listen. Cortex, 40, 118-132.

Davis, A., \& Annett, M. (1994). Handedness as a function of twinning, age and sex. Cortex, 30, 105-111.

Elias, L. (2004). Acknowledge the ambition, but look elsewhere for the alternatives. Cortex, 40, 133-135. 
Flöel, A., Buyx, A., Breitenstein, C., Lohman, H. \& Knecht, S. (2005). Hemispheric lateralization of spatial attention in right- and left-hemispheric language dominance. Behavioral Brain Research, 158, 269-275.

Flöel, A., Knecht, S., Lohman, H. et al. (2001). Language and spatial attention can lateralize to the same hemisphere in healthy humans. Neurology, 57, 1018-1024.

Francks, C., DeLisi, L. E., Fisher, S. E. et al. (2003). Confirmatory evidence for linkage of relative hand skill to 2p12-q11. American Journal of Human Genetics, 72, 499502.

Francks, C., Fisher, S. E., MacPhie, I. L. et al. (2002). A genome wide linkage screen for relative hand skill in sibling pairs. American Journal of Human Genetics, 70, 800805.

Francks, C, Maegawa, S., Laurén, J. et al. (2007). LRRTM1 on chromosome 2p12 is a maternally suppressed gene that is associated paternally with handedness and schizophrenia. Molecular Psychiatry, 12(12),1129-39.

Gangestad, S. W. \& Yeo, R. A. (1994). Parental handedness and relative hand skill: A test of the developmental instability hypothesis. Neuropsychology, 8, 572-578.

Geschwind, D. H., Miller, B. L., DeCarli, C. \& Carmelli, D. (2002). Heritability of lobar brain volumes in twins supports genetic models of cerebral laterality and handedness. Proceedings of the National Academy of Sciences, 99,3176-3181.

Gottesman, I. I. (1991). Schizophrenia Genesis: The Origins of Madness. New York: W.H. Freeman. 
Hoadley, M. F. \& Pearson, K. (1929). On measurement of the internal diameter of the skull in relation: I. To the prediction of its capacity, II. To the "pre-eminence" of the left hemisphere. Biometrika, 21, 85-123.

Jones, G. V. \& Martin, M. (2000). A note on Corballis (1997) and the genetics and evolution of handedness: Developing a unified distributional model from the sexchromosome gene hypothesis. Psychological Review, 107, 213-218.

Jones, G. V., \& Martin, M. (2001). Confirming the X-linked handedness gene as recessive, not additive: Reply to Corballis (2001). Psychological Review, 108, 811-813.

Jordan, H. E. (1911). The inheritance of left-handedness. American Breeders Magazine, 2, 19-29, 113-124.

Kang, Y. \& Harris, L. J. (1996). Accuracy of college students' reports of parental handedness. Laterality, 1, 269-279.

Kennedy, D. N., Ocraven, K. M., Ticho, B. S. et al. (1999). Structural and functional brain asymmetries in human situs inversus totalis. Neurology, 53, 1260-1265.

Kilshaw, D. \& Annett, M. (1983). Right and left-hand skill I: Effects of age, sex and hand preference showing superior skill in left-handers. British Journal of Psychology, 74, 253-268.

Klar, A. J. S. (1996). A single locus, RGHT, specifies preference for hand utilization in humans. Cold Spring Harbor Symposia on Quantitative Biology, 61, 59-65.

Knecht, S., Dräger, B., Deppe, M. et al. (2000a). Handedness and hemispheric language dominance in healthy humans. Brain, 123, 2512-2518. 
Knecht, S., Dräger, B., Deppe, M. et al. (2000b). Variability of the side and extent of language lateralization in the healthy population. Journal of Neurolinguistics, 13, 297-300.

Knecht, S., Dräger, B., Flöel, A. et al. (2001). Behavioural relevance of atypical language lateralization in healthy subjects. Brain, 124, 1657-1665.

Knecht, S., Jansen, A., Frank, A. et al. (2003). How atypical is atypical language dominance? Neuroimage, 18, 917-927.

Laland, K. N., Kumm, J., Van Horn, J. D. \& Feldman, M. W. (1995). A gene-culture model of human handedness. Behavior Genetics, 25, 433-445.

Layton, W. M. Jr. (1976). Random determination of a developmental process. Journal of Heredity, 67, 336-338.

McGee, M. G. \& Cozad, T. (1980). Population genetic analysis of human hand preference: Evidence for generation difference, familial resemblance and maternal effects. Behavior Genetics, 10, 263-275,

McGuire, W. J. \& MGuire, C. V. (1980). Salience of handedness in the spontaneous selfconcept. Perceptual and Motor Skills, 50, 3-7.

McKeever, W. F. (2000). A new family handedness sample with findings consistent with X-linked transmission. British Journal of Psychology, 91, 21-39.

McKeever, W. F. (2004). An X-linked three allele model of hand preference and hand posture for writing. Laterality, 9, 149-173.

McManus, I. C. (1980). Handedness in twins: A critical review. Neuropsychologia, 18, 347-355. 
McManus, I. C. (1985). Handedness, language dominance and aphasia: A genetic model. Psychological Medicine, Supplement 8.

McManus, I. C. (2004). Grappling with the Hydra. Cortex, 40, 137-139.

McManus, I. C. \& Bryden, M. P. (1992). The genetics of handedness, cerebral dominance and lateralization. In I. Rapin \& S. J. Segalowitz (Eds.) Handbook of Neuropsychology, vol. 6: Child Neuropsychology (pp 115-144) Amsterdam: Elsevier.

McManus, I. C., Martin, N., Stubbings, G. F., Chung, E. M. K. \& Mitchison, H. M. (2004). Handedness and situs inversus in primary ciliary dyskinesia. Proceedings of the Royal Society of London, Series B - Biological Sciences, 271 (1557) 25792582.

Medland, S. E., Duffy, D. L., Wright, M. J., Geffen, G. M., \& Martin, N. G. (2006). Handedness in twins: Joint analysis of data from 35 samples. Twin Research and Human Genetics, 9, 46-53.

Nonaka, S., Tanaka, Y., Okada, Y. et al. (1998). Randomization of left-right asymmetry due to loss of nodal cilia generating leftward flow of extraembryonic fluid in mice lacking KIF3B motor protein. Cell, 95, 829-827.

Okada, Y., Nonaka, S., Tanaka, Y. et al. (1999). Abnormal nodal flow precedes situs inversus in iv and inv mice. Molecular Cell, 4, 459-468.

Orlebeke, J. F., Knol, D. L., Koopmans, J. R., Boomsma, D. I. \& Bleker, O. P. (1996). Left-handedness in twins - genes or environment. Cortex, 32, 479-490. 
Pedersen, P. M., Jorgensen, H. S., Nakayama, H., Raaschou, H. O. \& Olsen, T. S. (1995). Aphasia in acute stroke: Incidence, determinants and recovery. Annals of Neurology, 38, 659-666.

Perelle, I. B. \& Erhman, L. (2005). On the other hand. Behavior Genetics, 35, 343-350.

Porac, C. \& Coren, S. (1979). A test of the validity of offsprings' report of parental handedness. Perceptual and Motor Skills, 49, 227-231.

Provins, K. A. (1997). Handedness and speech: A critical reappraisal of the role of genetic and environmental factors in the cerebral lateralization of function. Psychological Review, 104, 554-571.

Pujol, J., Deus, J., Losilla, J. M. \& Capdevila, A. (1999). Cerebral lateralization of language in normal left-handed people studied by functional MRI. Neurology, $\mathbf{5 2}$, 1038-1043.

Ramaley, F. (1913). Inheritance of left-handedness. The American Naturalist, 47, 730738.

Rife, D. C. (1940). Handedness with special reference to twins. Genetics, 25, 178-186.

Rife, D. C. (1950). An application of gene frequency analysis to the interpretation of data from twins. Human Biology, 22, 136-145.

Rutter, M. (1991). Autism as a genetic disorder. In P. McGuffin \& R. Murray (Eds.) The New Genetics of mental Illness ( pp. 223-244). London: Butterworth-Heineman.

Rutter, M., Moffitt, T. E. \& Caspi, A. (2006). Gene-environment interplay and psychopathology: Multiple varieties but real effects. Journal of Child Psychology and Psychiatry, 47, 226-261. 
Sicotte, N. L., Woods, R. P. \& Mazziotta, J. C. (1999). Handedness in twins: A metaanalysis. Laterality, 4, 265-286.

Siebner, H. R., Limmer, C., Peinemann, A. et al, (2002). Long term consequences of switching handedness: A positron emission tomography study on handwriting in “converted” left-handers. Journal of Neuroscience, 22, 2816-2825.

Smythe, P. \& Annett, M. (2006). Phonology and handedness in primary school: Predictions of the right shift theory. Journal of Child Psychology and Psychiatry, 47, 205-212.

Sommer, I. E.C., Ramsey, N. F., Mandl, R. C. W. \& Kahn, R. S. (2002). Language lateralization in monozygotic twin pairs concordant and discordant for handedness. Brain, 125, 2710-2718.

Steinmetz, H., Herzog, A., Schlaug. G., Huang, Y. \& Jäncke, L. (1995). Brain (a)symmetry in monozygotic twins. Cerebral Cortex, 5, 296-300.

Steinmetz, H., Volkman, J., Jäncke, L. \& Freund, H-J. (1991). Anatomical left-right asymmetry of language-related temporal cortex is different in left- and righthanders. Annals of Neurology, 29, 315-319.

Szaflarski, J. P., Binder, J. R., Possing, E. T. et al. (2002). Language lateralization in lefthanded and ambidextrous people: fMRI data. Neurology, 59, 238-244.

Tambs, K., Magnus, P. \& Berg, K. (1987). Left-handedness in twin families: Support of an environmental hypothesis. Perceptual and Motor Skills, 64, 155-170.

Tanaka, S., Kanzaki, R., Yoshibayashi, M., Kamiya, T. \& Sugishita, M. (1999). Dichotic listening in patients with situs inversus: brain asymmetry and situs asymmetry. Neuropsychologia, 37, 869-874. 
Trankell, A. (1955). Aspects of genetics in psychology. American Journal of Human Genetics, 7, 264-276.

Van Agtmael, T., Forrest, S. M., Del-Favero, J., Van Broeckhoven, C. \& Wlilliamson, R. (2003). Parametric and non-parametric genome scan analyses for human handedness. European Journal of Human Genetics, 11, 779-783.

Van Agtmael, T., Forrest, S. M. \&Williamson, R. (2001). Genes for left-handedness: How to search for the needle in the haystack? Laterality, 6, 149-164.

Van Agtmael, T., Forrest, S. M. \& Williamson, R. (2002). Parametric and non-parametric linkage analysis of several candidate regions for genes for human handedness. European Journal of Human Genetics, 10, 623-630.

Warren, D. M., Stern, M. Ravindranath, D., Dyer, T. D. \& Almasy, L. (2006). Heritability and linkage analysis of hand, foot and eye preference in Mexican Americans. Laterality, 11, 508-524.

Yeo, R. A. \& Gangestad, S. W. (1993). Developmental origins of variations in human hand preference. Genetics, 89, 281-296.

Zazzo, R. (1960). Les jumeaux: Le couple et la Personne. Paris: Presses Universitaire de France. 
Table 1. Data of Ashton (1982): Predicted and observed percentages of left-handers in family types for sons and daughters. (Sum chi squares for right-handers)

\begin{tabular}{|c|c|c|c|c|c|c|c|c|}
\hline \multirow{2}{*}{$\begin{array}{l}\text { Father } \\
x \\
\text { Mother }\end{array}$} & \multicolumn{5}{|c|}{ Sons } & \multicolumn{3}{|c|}{ Daughters } \\
\hline & $N$ & $\begin{array}{l}\text { Exp. } \\
\text { Percent }\end{array}$ & $\begin{array}{l}\text { Obs. } \\
\text { Percent }\end{array}$ & $\begin{array}{l}\text { Chi } \\
\text { square }\end{array}$ & $N$ & $\begin{array}{l}\text { Exp. } \\
\text { Percent }\end{array}$ & $\begin{array}{l}\text { Obs. } \\
\text { Percent }\end{array}$ & $\begin{array}{l}\text { Chi } \\
\text { square }\end{array}$ \\
\hline$R \times R$ & 1210 & 15.1 & 15.8 & 0.34 & 1220 & 12.8 & 13.2 & 0.14 \\
\hline$R \times L$ & 88 & 24.7 & 19.3 & 1.04 & 118 & 22.4 & 24.6 & 0.24 \\
\hline$L \times R$ & 128 & 23.6 & 21.1 & 0.34 & 143 & 21.3 & 14.7 & 2.94 \\
\hline \multirow[t]{3}{*}{$L \times L$} & 9 & 37.1 & 44.4 & 0.13 & 10 & 36.1 & 30.0 & 0.10 \\
\hline & & & Sum & $\begin{array}{l}1.86 \\
(0.59)\end{array}$ & & & & $\begin{array}{l}3.42 \\
(0.95)\end{array}$ \\
\hline & & Total & d.f. 3 & 2.45 & & & & 4.37 \\
\hline
\end{tabular}


Table 2. Data of McGee and Cozad (1980): Predicted and observed percentages of lefthanders in family types for sons and daughters. (Sum chi squares for right-handers)

\begin{tabular}{|c|c|c|c|c|c|c|c|c|}
\hline \multirow{2}{*}{$\begin{array}{l}\text { Father } \\
x \\
\text { Mother }\end{array}$} & \multicolumn{5}{|c|}{ Sons } & \multicolumn{2}{|c|}{ Daughters } & \multirow[b]{2}{*}{$\begin{array}{l}\text { Chi } \\
\text { square }\end{array}$} \\
\hline & $N$ & $\begin{array}{l}\text { Exp. } \\
\text { Percent }\end{array}$ & $\begin{array}{l}\text { Obs. } \\
\text { Percent }\end{array}$ & $\begin{array}{l}\text { Chi } \\
\text { square }\end{array}$ & $N$ & $\begin{array}{l}\text { Exp. } \\
\text { Percent }\end{array}$ & $\begin{array}{l}\text { Obs. } \\
\text { Percent }\end{array}$ & \\
\hline$R \times R$ & 489 & 23.2 & 22.9 & 0.02 & 570 & 17.5 & 17.4 & 0.00 \\
\hline$R \times L$ & 91 & 35.0 & 41.8 & 1.19 & 123 & 28.8 & 28.4 & 0.00 \\
\hline$L \times R$ & 130 & 33.5 & 30.0 & 0.47 & 131 & 27.3 & 29.0 & 0.13 \\
\hline \multirow[t]{3}{*}{$L \times L$} & 27 & 47.9 & 44.4 & 0.07 & 25 & 42.9 & 40.0 & 0.05 \\
\hline & & & Sum & $\begin{array}{l}1.74 \\
(0.94)\end{array}$ & & & & $\begin{array}{l}0.19 \\
(0.09)\end{array}$ \\
\hline & & Total & d.f.3 & 2.68 & & & & 0.28 \\
\hline
\end{tabular}


Appendix I. Predicted percentages of left-handed sons and daughters in four types of parental mating, for different levels of incidence of left-handedness in children and at two levels of incidence in parents (from Annett 2008).

a. Parental incidence $10 \%$ (fathers $10.6 \%$, mothers $9.4 \%$ )

\begin{tabular}{llllllllll}
\multicolumn{1}{c}{ Filial incidence } & \multicolumn{9}{c}{ Sons } \\
Percent & male/female & $R \times R$ & $R \times L$ & $L \times R$ & $L \times L$ & $R x R$ & $R \times L$ & $L \times R$ & $L \times L$ \\
5 & $5.3 / 4.7$ & 4.6 & 8.3 & 7.9 & 14.1 & 4.0 & 7.7 & 7.2 & 13.8 \\
10 & $10.6 / 9.4$ & 9.3 & 16.0 & 15.2 & 25.3 & 8.1 & 14.8 & 14.0 & 25.1 \\
15 & $16.0 / 14.0$ & 14.3 & 23.4 & 22.3 & 35.1 & 12.2 & 21.4 & 20.3 & 34.5 \\
20 & $21.5 / 18.5$ & 19.4 & 30.5 & 29.2 & 43.8 & 16.3 & 27.6 & 26.3 & 42.5 \\
25 & $27.0 / 23.0$ & 24.6 & 37.3 & 35.8 & 51.5 & 20.5 & 33.5 & 32.0 & 49.6 \\
30 & $32.5 / 27.5$ & 29.9 & 43.8 & 42.2 & 58.3 & 24.8 & 39.2 & 37.5 & 55.9 \\
35 & $38.0 / 32.0$ & 35.2 & 50.1 & 48.3 & 64.4 & 29.0 & 44.6 & 42.8 & 61.5 \\
40 & $43.5 / 36.5$ & 40.6 & 56.0 & 54.2 & 69.9 & 33.4 & 49.9 & 47.9 & 66.5
\end{tabular}

b. Parental incidence $20 \%$ (fathers $21.5 \%$, mothers $18.5 \%$ )

\begin{tabular}{llllllllll} 
Filial incidence & \multicolumn{1}{c}{ Sons } \\
Percent & male/female & $R \times R$ & $R \times L$ & $L \times R$ & $L \times L$ & $R x R$ & $R \times L$ & $L \times R$ & $L \times L$ \\
5 & $5.3 / 4.7$ & 4.0 & 7.3 & 6.8 & 12.2 & 3.4 & 6.6 & 6.2 & 11.8 \\
10 & $10.6 / 9.4$ & 8.3 & 14.2 & 13.4 & 22.3 & 7.1 & 12.9 & 12.2 & 21.8 \\
15 & $16.0 / 14.0$ & 12.8 & 21.0 & 19.9 & 31.3 & 10.8 & 18.9 & 17.9 & 30.2 \\
20 & $21.5 / 18.5$ & 17.6 & 27.7 & 26.4 & 39.4 & 14.6 & 24.6 & 23.3 & 37.6 \\
25 & $27.0 / 23.0$ & 22.6 & 34.1 & 32.7 & 46.8 & 18.5 & 30.2 & 28.7 & 44.3 \\
30 & $32.5 / 27.5$ & 27.7 & 40.4 & 38.8 & 53.5 & 22.5 & 35.6 & 33.9 & 50.3 \\
35 & $38.0 / 32.0$ & 32.9 & 46.5 & 44.8 & 59.6 & 26.6 & 40.8 & 39.0 & 55.8 \\
40 & $43.5 / 36.5$ & 38.2 & 52.4 & 50.6 & 65.1 & 30.8 & 45.9 & 44.0 & 60.9
\end{tabular}

